\title{
Editorial 2019
}

\author{
Sabina Lautensach ${ }^{1,2,3}$ \\ ${ }^{1}$ Editor-in-Chief of the Journal of Human Security, Librello, Basel, Switzerland \\ 2 Human Security Institute, Canada \\ 3 University of Northern British Columbia, Terrace, BC, V8G 4A2, Canada; E-Mail: salaut@gmail.com \\ Published: 18 February 2019
}

Dear Reader,

As I write this, most of North America is enduring another polar vortex, with temperatures plummeting far below past averages, compromising the security of individuals in numerous ways. At the same time, the latest meeting of the world's most powerful decision makers in Davos just concluded with another letdown, a glaring absence of any productive or decisive consensus about the security problems confronting humanity and the rest of the planet.

Climate change is of course only part of the multifaceted cluster of crises to human security that is sometimes referred to as the 'human predicament' [1] —interacting and self-reinforcing crises that include overpopulation-cumoverconsumption, waste of precious resources, rapidly deteriorating life-support systems, growing economic inequity and human rights abuses, increasing hunger, toxification of the planet, declining resources, an increasing threat of resource wars over fossil fuels and fresh water, a worsening epidemiological environment that raises the probability of unprecedented pandemics, along with persistent (and worsening in some cases!) racial, gender and religious prejudices that render the other problems more difficult to solve.

The many people who feel cheated and dumfounded by this conspicuous absence of responsible decision making now include Greta Thunberg, a sixteen-year-old Swedish student who addressed leaders at Davos as well as the preceding COP meeting at Katowice, Poland, accusing them in no uncertain language of failing to live up to the moral duties that come with their positions and their age. [2]

This charge of governmental failure has been expressed before. At the 2014 World Sustainability Forum we summarised the evidence suggesting that many governments fall short of their own broadly stated commitments towards sus- tainability and human security [3]. At the time we assessed the performance of governments against the standards set by the Millennium Development Goals, and concurrently discussed notions about the Sustainable Development Goals (SDGs) that were forthcoming. Most governments seemed to lag behind the real world in their perception of threats. The lag was observed by Barbara Tuchman [4] in her analysis of the history of the 14th century when she noted that "between the happening of a historical process and its recognition by rulers, a lag stretches, full of pitfalls." Such a lag has become even more painfully apparent since 2014 with increasingly obvious signs of ecological overshoot $[5,6]$, the rise of kakistocracies [7] and the consequences of their blunders, as well as a palpable aggravation of humanity's 'war against nature' as documented by Ronnie Hawkins [8].

The charge of failure amounts to this: In spite of the numerous warnings by scientists and the UN of the deleterious effects of overshoot, the world's governments have neither acknowledged its existence nor attempted to mitigate its impact or to adjust its five driving factors-population growth, economic growth, technological expansion, arms races and growing inequity [9].

The notion of governmental failure arises from several considerations. First, the public has numerous expectations of government that are fulfilled less and less. Those expectations are widely shared on the basis of familiar historical precedents that set certain performance standards, where responsible and farsighted persons in positions of leadership enacted policies that favoured social justice, economic stability, equitable quality of lives, and sustainable peace and security. Examples include the Roosevelt presidents, the founders of the European Union, the founders of the League of Nations and the United Nations, Nelson Mandela and various other notable leaders. They were 
able to overcome the confines of entrenched beliefs that have historically led many average administrations into failure [10].

Secondly, many governments appear unable to adjust their promises to what is realistically possible. Expectations in the electorates are kept high partly by inflated notions of the possible, fuelled by ideologically influenced beliefs in materialistic progress and endless growth of populations and economies. To a large extent those cornucopian notions proved unrealistic once humanity entered overshoot, though to the scientifically literate minority they must have always seemed unsound. Other notions of the possible are fed by democratic ideals that form the basis of constitutions and political norms in Western societies. Those ideals are jeopardised to the extent that electorates have become undereducated, disinformed, disenfranchised and misled by demagogues and corporate interest groups and the mass media they control [11]. Governments were increasingly tempted to cater to such inflated expectations-restraining themselves to realistic promises seemed politically imprudent. This dilemma provides a partial explanation for the politicians' obstinate insistence on economic growth as an absolute requirement for progress while every schoolchild understands that nothing in the physical universe can grow forever.

Thirdly, many present-day governments routinely break their own campaign promises as well as established rules of procedure such as court rulings against them. Ideals of honesty and fair dealing that are normally kept alive through shared myths and values in a society have been gradually eroded [12]. Campaign promises on both sides (in First-Pastthe-Post electoral systems such as in North America there are almost always only two sides) are habitually inflated to unrealistic proportions during election campaigns, proportions that often necessitate subsequent repudiation. By and large the public have come to expect such disappointments. The resulting disillusionment on the sides of both governments and the governed is particularly obvious in North America where the "violence of organised forgetting" has depoliticised, homogenised and disenfranchised the citizenry [13].
Outright failure, however, includes more than breaking promises that were untenable from the start, or breaking even those that realistically could have been kept with a modicum of tenacity. It extends to a lack of vision and the repudiation of moral responsibility; it is often aided by professional incompetence, ignorance and self-interest. It raises the question, retrospectively, to what extent a particular governmental failure might have been caused by incompetence, neglect or actual malfeasance, respectively. The examples listed in Table 1, selected from a much more comprehensive list [3], illustrate the point. The main standard or norm on which these examples are assessed is the protection, restoration, improvement or stabilisation of human security in one or several of its four pillars [14]; the standard extends to the fulfilment of professional duties, as to prevent injustice or economic, environmental or physical harm. Beyond that, the examples show the range of diverse effects or violations that governmental failure can exert-from procedural or distributive injustice through economic harm for entire societies (especially their future generations), damage to vital ecological support structures, to chronic endangerment of public health. Failure can occur by commission or it can involve mere omission, as in the example listed at the bottom.

Some of the failures are particular evident in the US or Canada, as in the cases of permissive emission policies and the gagging of scientists. Others, such as trade liberalisation, occur much more globally. Likewise, their effects range from regional to global. Some countries present notable exceptions, indicating what can be accomplished when governments are empowered and morally conscientious enough. An example is the development of labour rights in the EU with the aim to reduce stress at the workplace, saving millions in public health expenditures; in North America, the trend actually goes in the opposite direction [15]. Unfortunately such positive examples are unlikely to accomplish a global turnaround as long as they remain exceptions.

Table 1. The failure of governments can manifest in numerous ways and result in diverse detriments to human security. These four manifestations compromise human security in its environmental, economic, health-related and political pillar, respectively.

\begin{tabular}{ll}
\hline \multicolumn{1}{c}{ MANIFESTATIONS } & \multicolumn{1}{c}{ EVIDENCE } \\
\hline $\begin{array}{l}\text { Collusion in the delaying, distorting, denying, discrediting of evidence } \\
\text { for anthropogenic climate change }\end{array}$ & $\begin{array}{l}\text { Organised public misinformation [16]; Canadian federal policies [17]; } \\
\text { one result is the 'culture gap' [18]; }\end{array}$ \\
$\begin{array}{ll}\text { Subsidising unsustainable industries and refusing to subsidise } \\
\text { sustainable ones }\end{array}$ & $\begin{array}{l}\text { Fossil fuel production versus solar and other alternative energy } \\
\text { sources; no plans for coping with "peak everything" [19] }\end{array}$ \\
$\begin{array}{ll}\text { Perpetuating the monopolistic production and continued marketing of } \\
\text { unhealthy foods }\end{array}$ & $\begin{array}{l}\text { Dominant unsustainable agricultural practices and their legislative } \\
\text { protection; continued incidence of obesity and malnutrition [20] }\end{array}$ \\
$\begin{array}{ll}\text { Refusing to take effective steps towards demilitarisation and to stop } \\
\text { arms races, inhumane weapons and torture }\end{array}$ & $\begin{array}{l}\text { Absence of learning from history [21]; expansionist policies by NATO } \\
\text { and Russia; failure of the Canadian government to sign the 2002 } \\
\text { Optional Protocol to the Conventions Against Torture, as promised in } \\
\text { 2006. Disproportionate budgeting for military. }\end{array}$ \\
\hline
\end{tabular}


In order to find how these failures might be mitigated, it helps to look for some explanations. Much has been speculated about possible causes, especially where the failure involves intentional action and underlying negligence or malfeasance. Causative factors include counterproductive ideologies or worldviews, such as cornucopianism, national chauvinism or cultural parochialism, or corrupt practices and special interests. Many spectacular failures are caused by policies that favour the short-term interests of corporate groups and not the public good, suggesting possible corruption and morally sanctioned greed [22]. Conversely, inadvertent failure could be caused by a lack of vision, lack of confidence, excessive caution, lack of information, or basic incompetence [23]. The latter includes status quo bias favouring the path of least resistance. Among the citizenry, pervasive manifestations of cognitive bias, mental habits and moral ineptitudes tend to hamper the transition to sustainable life styles [24] and permit failing governments to continue. However, at the level of government it seems appropriate to expect a higher standard. To the extent that positive precedents suggest that governmental success is possible in principle, we exclude scenarios where prohibitive circumstances compromise a government's odds to succeed. In other words, our charges of failure only apply to governments with a realistic potential of achievement under their specific circumstances. As even my small list of examples suggests, this still leaves plenty of occasions.

The most concise, lucid and comprehensive explanation for the failure of government that I have come across was proposed by Sheila Collins [25]. She offers three areas of explanations for the curious phenomenon that political and economic institutions continue with counterproductive, anachronistic policies that basically ignore climate change, despite their harmfulness having been demonstrated by numerous scientific analyses beyond reasonable doubt.

Her first strand of thinking focuses on the central role that energy systems play in the development of societies. As described by Débeir, Deléage and Hémery [26], dominant energy systems in every historical era led to the construction of political and economic regimes that resisted change. Those systems prioritise a single particular form of energy for the reproduction of human life, human work, and thus our civilization. The harnessing of energy and its transformation serves as a foundation not only of all human societies but it underlies the functioning of all life. At various historical times human societies have used as energy sources individual human labour, collectivized and mechanized human labour, hydraulic technology, and the thermal energy of wood and fossil fuels via steam and electric technologies. Each energy source gave rise to a characteristic 'energy system', including the development of a coercive state, feudal stratification, or capitalist class divisions, respectively. Each energy system came with its characteristic elites and political power structures. Each ruling elite regarded as their main mission the development of increasingly sophisticated technology for the use of the dominant energy source in preference to all other alternatives, until it has reached its saturation point or until society collapses. Thus, an energy system continues to dominate society through the efforts of elites to extend its life, which include not only innovative technologies but at times older technologies - such as, in our time, slave labour, indentured servitude and sweatshops being put to use in the effort to prolong the life-cycle of the fossil fuel system. The emergence of energy-related elites in the governing structures of the OECD countries during the twentieth century explains various particular national policies that contravened the much-invoked principles of justice and peaceful cooperation, not to mention collective sustainable survival; examples include the 1953 regime change in Iran, alliances with the Saudi royal family, oil wars in the Middle East, the rise of new 'Petro states', the suppression of climate science, ongoing subsidies for fossil fuel industries, and the opening of fossil fuel reserves in protected nature preserves while renewable energy was always discredited as "too expensive".

Collins' second strand of thinking rests on Thomas Kuhn's [27] theory of paradigm shifts in science, applied to the realm of political ethics by cognitive scientist George Lakoff (2008). Kuhn showed that science normally works on the basis of deeply held beliefs or paradigms that are slow to change and are only transformed when a tipping point or critical measure of cognitive dissonance is reached, at which existing paradigms lack sufficient explanatory power. In this way, mainstream science has a means of correcting itself, albeit not always very quickly. Neither economics nor politics as academic fields work that way, despite their vocal efforts to be recognized as 'sciences'. The state system and the capitalist economy are still dominated by the Enlightenment paradigm under which they emerged, whereas science substantially moved on from the Enlightenment a century ago. Thus, the two institutional systems through which all the major decisions are made about ordering our collective affairs and managing our energy systems are still operating on the basis of a paradigm that science has long recognized as dysfunctional, myopic and suicidal. In search of an explanation for that collective handicap, Lakoff [28] invoked the largely unconscious workings of human reason, based on image schemata and metaphors, as well as culturally contingent narratives. We make 'sense' of facts by fitting them into 'frames'-or not, as the case may be. Whatever does not fit our cognitive frames tends to remain unrecognized or even unimagined. Our thinking about governance and the economy is still dominated by Enlightenment frames because the institutions that embody those constructs continue to enforce them, through normative rules and incentives. The cognitive tipping points for paradigm shifts are still out of reach because the cognitive dissonance has not been brought to our awareness.

A third strand extends Lakoff's cognitive theory to an analysis of the Enlightenment paradigm and its continuing influence on governance and economics, distorting the new scientific insights about how the planetary system actually works, and impeding our timely transition. In the areas of 
politics and international relations, examples for counterproductive dominant Enlightenment frames, according to Lakoff, include the patriarchal family, ingroup-outgroup hierarchies, the sovereign individuality of states, game theory, and the exemption of economics from political scrutiny. In economics, examples include rational actor theory, market autonomy, absence of limits to property and growth, and corporate 'personhood'.

The day-to-day confrontation with the reality of failing governance led us to explore educational solutions and coping strategies [3]. They depend in part on where the main reason for government failure is located in a particular instance-be it negligence, incompetence or malfeasance. In her analysis, Collins evidently comes down on the side of incompetent malfeasance, with considerable variation among specific examples. Decision makers pursue the perpetuation of the present power structures as a deliberate priority, regardless of the consequences for humanity and the Earth.

Collins concludes her critique with some perceptive and constructive suggestions on how those constraints could be overcome. One is the development of the personal habit of reflective cognition focusing on terms, metaphors and slogans that are used repetitively by ruling powers and the mass media. This interrupts the reflexive use of such terms

\section{References and Notes}

[1] Ehrlich PR. Ecoethics: Now central to all ethics. Journal of Bioethical Inquiry. 2009;6(4):417. doi:10.1007/s11673-009-9197-7.

[2] On Friday, 14 December 2018, fifteen year old Greta Thunberg, a Swedish schoolgirl, delivered a riveting accusation at the COP24 Conference of world leaders in Kattowice, Poland. "You are not mature enough to tell it like it is" she admonished the audience, mostly elderly men, "even that burden you leave to us children." Meanwhile, up to 20,000 school children went on strike in OECD countries, protesting against the failure of the world's governments to take effective action against climate change.;. Available from: https://m.youtube.com/watch?v=HzeekxtyFOY.

[3] Lautensach A, Lautensach S. Education for Sustainability: How Can Educators Address the Failure of Government? In: The 4th World Sustainability Forum. Multidisciplinary Digital Publishing Institute; 2014. Available from: http://sciforum.net/conference/wsf4/paper/2450.

[4] Tuchman BW. A distant mirror: The calamitous 14th century. Ballantine Books; 1979.

[5] Catton WR. Overshoot: The ecological basis of revolutionary change. University of Illinois Press; 1982.

[6] Ehrlich PR, Ehrlich AH. Can a collapse of global civilization be avoided? Proceedings of the Royal Society B: Biological Sciences. 2013;280(1754):20122845. doi:10.1098/rspb.2012.2845.

[7] Wikipedia defines a kakistrocacy as "a system of government which is run by the worst, least qualified, or most unscrupulous citizens"; from Greek kakistos = worst, superlative of kakos = bad.;

[8] Hawkins R. Our war against nature. In: Lautensach A, Lautensach S, editors. Human Security in World Affairs: Problems and Opportunities. Vienna, Austria: Caesarpress; 2013. pp. 227-248. An updated and expanded version of this chapter is forthcoming with the second edition. An updated and expanded version of this chapter is forthcoming with the second edition.

[9] Coates JF. The sixteen sources of environmental problems in and replaces them with their reflected use. Collins names as examples the 'war on terror' and other martial metaphors, 'enemy of the state', and fatalistic trends toward adaptation in the face of climate change. On the constructive side, some frames require to be reinforced and advocated; examples include 'biopiracy', 'ecocide', and 'development' in its true, sustainable sense. In general, people's fear of reframing must be overcome to prevent advocates from falling into the habit of using their opponents' frames. This danger arises whenever the ruling powers co-opt a term for their own agenda, as in the case of 'sustainable development'. The frames of 'terrorism' or 'scientific certainty' are used also for stereotyping and vilifying entire movements.

I notice with some gratification that in her efforts to identify solutions Collins converged on education and learning. I agree with her optimistic assessment that the power of Enlightenment thinking is waning worldwide, that its life time is running out. Evidence comes from rising social movements and indigenous empowerment, just to name two emerging phenomena. Unfortunately we cannot regard that as a reason for complacency, because evidently time is running short for many of our collective aspirations, including human civilization and its sustainable security.

Peace and Light!

Sabina W. Lautensach the 21st century. Technological Forecasting and Social Change. 1991;40(1):87-91. doi:10.1016/0040-1625(91)90069-R.

[10] Tuchman BW. A distant mirror: The calamitous 14th century. Ballantine Books; 1979.

[11] Hinson CL. Negative information action: Danger for democracy. American behavioral scientist. 2010;53(6):826-847. doi:10.1177/0002764209353276.

[12] Chomsky N. Failed states: The abuse of power and the assault on democracy. Metropolitan Books; 2007.

[13] Giroux HA. The violence of organized forgetting: Thinking beyond America's disimagination machine. City Lights Publishers; 2014.

[14] Lautensach AK. Expanding human security. The Australasian Journal of Human Security. 2006;2(3):5.

[15] Stiglitz J. Inequality is not inevitable. New York Times. 2014;27:12. Available from: http://opinionator.blogs.nytimes.com/category/thegreat-divide/.

[16] Oreskes N, Conway EM. Merchants of doubt: How a handful of scientists obscured the truth on issues from tobacco smoke to global warming. Bloomsbury Publishing USA; 2011.

[17] Schindler D. Canadian science goes down the drain. The Tyee (14 May 2014) and Royal Society of Canada Bulletin (Spring 2014);

[18] Ehrlich PR, Ehrlich AH. The culture gap and its needed closures. International Journal of Environmental Studies. 2010;67(4):481-492. doi:10.1080/00207233.2010.510825.

[19] Heinberg R. Peak everything: waking up to the century of declines. New Society Publishers; 2010.

[20] Cribb J. The coming famine: the global food crisis and what we can do to avoid it. Berkeley, CA, USA: University of California Press; 2010.

[21] Culpeper R. What remains unlearned from the First World War. Embassy News; 2016. Available from: http://www.embassynews.ca/opinion/2014/08/26/what-remainsunlearned-from-the-first-world-war/45953.

[22] Rees WE. Avoiding collapse: An agenda for sustainable degrowth and relocalizing the economy. Ottawa, Canada: Canadian Centre for 
Policy Alternatives, BC Office; 2014.

[23] On 24 July 2014, ahead of the presidential elections, Turkish Deputy Prime Minister Bulent Arinc exhorted Turkish women to limit their laughter in public. The reaction was a storm of very public hilarity. It reflects on a government's mechanisms of quality control when individuals of such monumental incompetence are allowed to advance into its highest echelons.;

[24] Lautensach A. Environmental ethics for the future: rethinking education to achieve sustainability. Saarbruecken, Germany: Lambert Academic Publishing; 2010
[25] Collins S. Closing the boxes, enlarging the circles: toward a new paradigm of global governance and economy. Transaction Publishers; 2011.

[26] Débeir JC, Deléage JP, Hémery D. In the Servitude of Power: Energy and Civilization through the Ages, trans. London, UK: Zed Books 1986.

[27] Kuhn TS. The structure of scientific revolutions. Chicago, IL, USA: University of Chicago Press; 1996.

[28] Lakoff G. The political mind: why you can't understand 21st-century politics with an 18th-century brain. London, UK: Penguin; 2008. 